\title{
Inheritance of Resistance to Downy Mildew in Sweet Basil
}

\author{
Robert M. Pyne \\ New Use Agriculture and Natural Plant Products Program, Department of Plant Biology and \\ Pathology, Rutgers University, 59 Dudley Road, New Brunswick, NJ 08901
}

\author{
Adolfina R. Koroch \\ Science Department, Borough of Manhattan Community College, The City University of New York, \\ 199 Chambers Street, New York, NY 10007 \\ Christian A. Wyenandt \\ Department of Plant Biology and Pathology, Rutgers University, Rutgers Agricultural Research and \\ Extension Center, 121 Northville Road, Bridgeton, NJ 08302 \\ James E. Simon ${ }^{1}$ \\ New Use Agriculture and Natural Plant Products Program, Department of Plant Biology and \\ Pathology, Rutgers University, 59 Dudley Road, New Brunswick, NJ 08901
}

\begin{abstract}
AdDITIONAL INDEX WORDs. genetic resistance, major genes, digenic epistasis, plant breeding, Ocimum basilicum, Peronospora belbahrii

Abstract. Sweet basil (Ocimum basilicum) is one of the most economically important culinary herbs in the world, yet global production has become increasingly challenging due to the destructive disease downy mildew (Peronospora belbahrii). Although multiple sources of resistance have been identified, there are no resistant sweet basil cultivars with a commercially acceptable chemotype and phenotype available. The commercial basil cultivar Mrihani (MRI) was identified as resistant and crossed with a Rutgers University susceptible sweet basil inbred line (SB22) to generate a full-sibling family. To determine the mode of inheritance for resistance to downy mildew in basil, six related generations of the MRI $\times$ SB22 family were evaluated using a disease severity index (DSI) at northern and southern New Jersey locations over 2 years. All siblings in the $\mathrm{F}_{1}$ and $\mathrm{BC}_{1} \mathrm{P}_{2}$ generations were resistant $(0.33>$ DSI) providing strong evidence that inheritance of resistance from MRI was conferred by dominant alleles. Segregation ratios in the $F_{2}$ and backcross to the susceptible parent $\left(\mathrm{BCP}_{1}\right)$ generations demonstrated chi-square goodness of fit to the two-gene complementary $\left(\mathrm{F}_{2}: P=0.11, \mathrm{BC}_{1} \mathrm{P}_{1}: P=0.04\right)$ and recessive epistatic $\left(\mathrm{F}_{2}: P=0.03, \mathrm{BC}_{1} \mathrm{P}_{1}: P=0.63\right)$ models. Further analyses of gene effects using a weighted six-parameter scaling test provided evidence that nonallelic additive $\times$ additive and additive $\times$ dominant gene effects were highly significant $(P<0.001)$ and resistance reducing. This is the first report of heritable genetic resistance that can be introduced to sweet basil without the issue of sterility barriers. Plant breeding strategies using the MRI $\times$ SB22 family should exploit dominant gene action and remove recessive, resistance-reducing alleles from the population.
\end{abstract}

Basil (Ocimum sp.) is a highly diverse genus (Vieira et al., 2003) that includes at least 64 species (Paton et al., 1999), several of which are among the most widely cultivated and consumed herbs worldwide (Simon et al., 1990). In the United States, Israel, and Europe, commercial sweet basil is readily identified by a distinct phenotype and chemotype used in the fresh, dried, and culinary industries (De Masi et al., 2006; Simon et al., 1990). Downy mildew has become a devastating disease of commercial sweet basil around the world and has

Received for publication 9 Apr. 2015. Accepted for publication 24 June 2015. Funds for this research and in support of a graduate assistantship/doctoral degree for the senior author were provided by USDA/SCRI grant no. 201151181-30646.

We thank Ed Dager and Mark Peacos for their assistance in our field and greenhouse studies and U.S. commercial basil growers and basil buyers for their continued support. We thank Dan Ward and Stacy Bonos, Rutgers University, for fruitful discussions relative to experimental design and statistical analyses. We thank the New Jersey Agricultural Experiment Station and the Rutgers Cooperative Extension Service for also providing funds in support of this work (NIFA HATCH project reports NJAES 12131 and 1005685).

${ }^{1}$ Corresponding author. E-mail: jimsimon@rci.rutgers.edu or jesimon123@ gmail.com. severely impacted major growing regions in the United States since 2007 (Roberts et al., 2009; Wyenandt et al., 2010). A genus-specific host range limits $P$. belbahrii infection to basil species and excludes other members of the Lamiaceae family (Belbahri et al., 2005; Thines et al., 2009). Pathogenesis occurs during extended periods of leaf wetness and high humidity, which facilitate sporangia germination and entry through host stomata (Garibaldi et al., 2007; Koroch et al., 2013). Persistence of these environmental conditions results in profuse sporulation from the abaxial leaf surface and rapid disease progress leading to complete crop loss (Roberts et al., 2009). The capacity of $P$. belbahrii to persist on both seed (Garibaldi et al., 2004a) and transplants (Farahani-Kofoet et al., 2012) provides versatility to this species of downy mildew, which has facilitated its worldwide dissemination (Blomquist et al., 2009; Garibaldi et al., 2004b; Kanetic and Vasiliou, 2014; Martinezde la Parte et al., 2009; McLeod et al., 2006; Nagy and Horvath, 2011).

Conventional and organic control methods have been explored and several conventional fungicides have resulted in reduced disease severity; however, organic controls tested to 
date remain ineffective (Homa et al., 2014; Mersha et al., 2012). The efficacy of chemical control agents is dependent on many factors including host developmental stage, application rate/ interval, environmental conditions, and inoculum levels. The foliar application of pesticides in sweet basil has a number of disadvantages including the chemical residuals (Gilardi et al., 2013), pathogen selection pressure (Cohen et al., 2013), and increased resources required for repeated applications. The existence of $P$. belbahrii races has not been reported. However, recent discovery of oospores (Cohen et al., 2013) suggests the potential for sexual reproduction and eventual evolution of new pathogen races. Integration of downy mildew-resistant sweet basil cultivars into pest management strategies represents a more sustainable control strategy that is advantageous to environmental, public health, and economic interests.

Host resistance to basil downy mildew was first reported in 2010 from field evaluations in which all $O$. basilicum cultivars and breeding lines were highly susceptible (Wyenandt et al., 2010). Sporulation was reduced in multiple cultivars of $O$. Xcitriodorum, while sporulation and chlorosis were absent on leaves of three similar cultivars of $O$. americanum (Wyenandt et al., 2010). To confirm these field observations and identify new sources of resistance and tolerance to basil downy mildew, a rapid screening protocol using a controlled environment was developed (Pyne et al., 2014).

Greenhouse evaluations of the U.S. Department of Agriculture National Plant Germplasm System (USDA-NPGS) germplasm demonstrated extensive susceptibility among $O$. basilicum accessions with the exception of accessions PI 172996, PI 172997, and PI 172998. Sporulation was not observed on leaves of these accessions. However, presence of disease symptoms (i.e., chlorosis and necrosis) in greenhouse screenings (Pyne et al., 2014) and presence of sporulation in field evaluations (James E. Simon, unpublished data) diminished the breeding value of these lines. Greenhouse screening has been essential to the identification of multiple resistant Ocimum accessions such as PI 652053 (Farahani-Kofoet et al., 2014; Pyne et al., 2014). However, these accessions are different species from $O$. basilicum and breeding is limited by sexual incompatibility and $\mathrm{F}_{1}$ hybrid sterility. The commercial cultivar Mrihani [Ocimum sp. (Horizon Seed Co., Williams, OR)] is a methyl chavicol chemotype with highly serrate and undulate leaves that was initially identified as downy mildew resistant using the rapid screening approach (Pyne et al., 2014). Despite a substantial difference in aroma, flavor, and phenotype, this cultivar is sexually compatible with sweet basil and could be used to facilitate the development of subsequent generations from a fertile $\mathrm{F}_{1}$.

For disease resistance breeding strategies to be most effective, they must be supported by inheritance studies that measure disease response across multiple generations, environments, and years (Holland et al., 2003). Such studies can be used to determine number of genes involved and elucidate gene action, which is essential to the adoption of an effective breeding method. True leaf downy mildew resistance in Brassica species has been attributed to a single dominant gene in multiple reports (Farnham et al., 2002; Jensen et al., 1999; Mahajan et al., 1995; Monteiro et al., 2005; Natti et al., 1967). Carlsson et al. (2004) determined a single recessive gene to be responsible for resistance in cotyledons of Brassica oleracea. Traits controlled by Mendelian genes are advantageous to plant breeders because rapid gain can be achieved with fewer selection cycles. However, in many cases gene action is complicated by multiple genes acting independently or interacting in a nonallelic or epistatic fashion (Hayman, 1958; Jinks and Jones, 1957; Mather and Jinks, 1971).

Peronospora belbahrii is an emerging pathogen of Ocimum species and inheritance of resistance has not been characterized. When prior knowledge of gene action is unavailable, it is important that an appropriate mating design is selected to capture as much genetic variation as possible through use of multiple populations from the same or different parents (Mather and Jinks, 1971). The development of six related generations derived from two inbred lines with differential response to a particular trait of interest provides a metrical system for partitioning of gene effects using scaling tests (Hayman, 1958; Mather and Jinks, 1971). This classic mating design has proven effective in determinations of heritability and gene action when characterizing new sources of disease resistance (Tetteh et al., 2013a, 2013b). The objective of this study was to investigate the mode of inheritance for resistance to downy mildew in a segregating full-sibling sweet basil family. Results provide the basis by which to design the appropriate breeding and selection strategies for the development of downy mildew resistance in sweet basil.

\section{Materials and Methods}

Plant material and controlled crosses. The two parent genotypes in this study were selected based on a consistent, differential response to downy mildew through repeated field and greenhouse evaluations at Rutgers University greenhouses. Inbred sweet basil breeding line SB22 (Fig. 1A) was found to be highly susceptible, while the cultivar Mrihani (Fig. 1B) demonstrated resistance with no sporulation and little or no chlorosis. The latter genotype was therefore selected as the resistant parent and designated MRI following two generations of self-pollination. Lacking any prior knowledge with regard to the genetic basis by which MRI confers resistance, a sixgeneration mating design consisting of susceptible parent [SB22 (Fig. 1A)], resistant parent [MRI (Fig. 1B)], $F_{1}$ [maternal parent $=$ MRI (Fig. 1C) $], F_{1} R$ (maternal parent $\left.=S B 22\right), F_{2}($ Fig. $1 \mathrm{H}-\mathrm{K})$, backcross to SB22 [BC $\mathrm{P}_{1}$ (Fig. 1D-G)], and backcross to $\mathrm{MRI}\left(\mathrm{BC}_{1} \mathrm{P}_{2}\right)$ generations were selected to allow for measurement of potential additive, dominant, and epistatic gene effects (Mather and Jinks, 1971). Crosses were made in early morning hours by emasculation of unopened (immature) flower whorls followed by hand pollination 24 and $48 \mathrm{~h}$ later. Glassine bags (Seedburo, Des Plaines, IL) were used to cover emasculated flowers to prevent any incidental outcrossing from taking place. In total, 30 susceptible parent (SB22), 30 resistant parent (MRI), $30 \mathrm{~F}_{1}, 30 \mathrm{~F}_{1} \mathrm{R}, 300 \mathrm{~F}_{2}, 180 \mathrm{BC}_{1} \mathrm{P}_{1}$, and $144 \mathrm{BC}_{1} \mathrm{P}_{2}$ individuals were used in this study. Seeds were germinated on blotting paper moistened with sterile distilled water and incubated at $30 / 20{ }^{\circ} \mathrm{C}$ corresponding to a $12-\mathrm{h}$ light/dark schedule. Seedlings were transferred to a 72 - or 128-celled flat with growing mix (Fafard Grow Mix 2; Sun Gro Horticulture, Agawam, MA) on emergence of cotyledons and maintained under greenhouse conditions at the Rutgers Research Greenhouses in New Brunswick, NJ, until field establishment.

FiELd ESTABLISHMENT AND EXPERIMENTAL DESIGN. This study was conducted at two locations over 2 years. In year 1 , an exploratory field experiment was initiated in which five generations: SB22, MRI, $F_{1}, F_{1} R, F_{2}$, and $B_{1} P_{1}$ were evaluated 


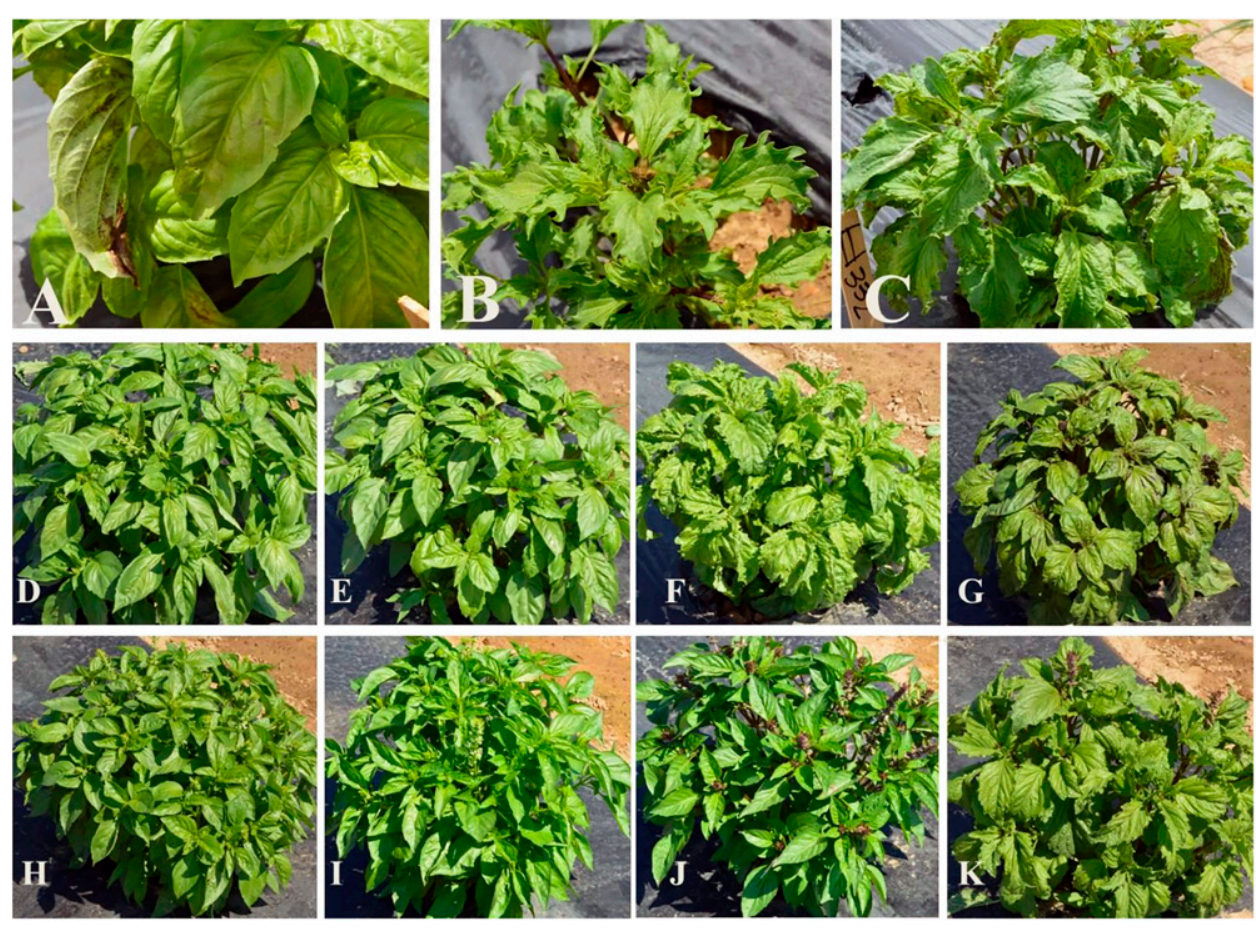

Fig. 1. Phenotypic variation in the basil MRI $\times$ SB22 full-sib family: (A) SB22 (susceptible parent), (B) MRI (resistant parent), (C) $\mathrm{F}_{1}$ (resistant), (D-G) $\mathrm{BC}_{1} \mathrm{P}_{1}$ siblings (backcross to $\mathrm{SB} 22$ ), and (H-K) $\mathrm{F}_{2}$ siblings.
Control plots and guard rows consisting of highly susceptible $O$. basilicum commercial cultivar DiGenova were included within each block to ensure uniform inoculum and aid in the determination of appropriate rating dates.

To ensure that the response variable was strictly a measurement of reaction to $P$. belbahrii, evaluations were made on the basis of percent sporulation. A five-point ordered categorical scale $(0-4)$ was used in which $0=$ no sporulation, $1=1 \%$ to $10 \%$ sporulation, $2=11 \%$ to $25 \%$, $3=26 \%$ to $50 \%$, and $4=51 \%$ to $100 \%$. This scale facilitated rapid scoring of multiple leaves from individual plants, while providing a repeatable and representative measure of disease reaction on an individual plant basis. Six mature leaves were detached from each plant and assigned a score from which a DSI (Gilardi et al., 2013; Mahajan et al., 1995; Shashikumar et al., 2010) was calculated on a single-plant basis using the equation:

at a single site, the Rutgers Agricultural Research and Extension Center (RAREC) in Bridgeton (southern New Jersey). In year 2, this experiment was repeated with six generations: SB22, MRI, $\mathrm{F}_{1}, \mathrm{~F}_{1} \mathrm{R}, \mathrm{F}_{2}, \mathrm{BC}_{1} \mathrm{P}_{1}$, and $\mathrm{BC}_{1} \mathrm{P}_{2}$ from new crosses at RAREC and at a second location, the Snyder Research and Extension Farm in Pittstown (northern New Jersey). The two locations in this study are separated by $\approx 118 \mathrm{~km}$ and are known to have different environmental conditions (i.e., temperature and rainfall patterns). RAREC is located in the outer coastal plains of southern New Jersey in a sandy loam soil type, while the northern location has a silt loam soil type. All genotypes evaluated in year 2 were cloned by vegetative propagation, with one clone per genotype represented at each of the two locations to provide a measure of genotype by environment interaction. Clones were transplanted in single rows with $1-\mathrm{m}$ spacing at both locations to allow for single plant evaluations.

All field experiments were conducted in raised beds with $0.032-\mathrm{mm}$ plastic mulch spaced on $1.5-\mathrm{m}$ centers and with drip irrigation applied as needed. Fertilizers, insecticides, and herbicides were applied as needed and according to local standard production practices at each location in both years of the study. Field experiments were arranged in a randomized complete block design with progeny of each generation divided equally into three blocks. Thus, each block contained 10 plants per parent, 10 plants per $F_{1}, 10$ plants per $F_{1} R, 100$ plants per $F_{2}$, 60 plants per $\mathrm{BC}_{1} \mathrm{P}_{1}$, and 48 plants per $\mathrm{BC}_{1} \mathrm{P}_{2}$.

InOCUlation AND Disease RATING. Peronospora belbahrii inoculum was consistently present at the northern and southern New Jersey locations in both years of this study and was consistent with other related studies on basil downy mildew conducted at these sites (Homa et al., 2014; Wyenandt et al., 2010). Overhead irrigation was regularly applied to maintain leaf wetness and relative humidity during extended dry periods.
$\mathrm{DSI}=\frac{\sum(\text { single leaf } \quad \times}{\text { (number of leaves scored } \times \text { maximum disease rating })}$

Disease progress was monitored using susceptible control plots. Initial disease evaluations were made on observance of sporulation on all control plots and subsequent evaluations were made with increasing disease severity. Disease ratings were made on three dates (8 Aug., 26 Aug., and 15 Sept.) in 2013 and four dates (25 Aug. and 10 Sept. in southern New Jersey; 28 Aug. and 16 Sept. in northern New Jersey) in 2014 for a total of seven disease rating over 2 years. For each year $\times$ location combination, disease ratings data corresponding to the highest family mean DSI, or greatest disease selection pressure, were selected for subsequent statistical analysis. These ratings were performed $33 \mathrm{~d}$ after planting (DAP) in southern New Jersey in 2013, 49 DAP in southern New Jersey in 2014, and 53 DAP in northern New Jersey in 2014.

Statistical AnAlysis. Means, variances, and frequency distributions of DSI scores among generations were calculated separately for each of the three rating dates selected over 2 years using PROC UNIVARIATE (SAS version 9.4; SAS Institute, Cary, NC). Bartlett's homogeneity of variances tests were performed using the F2 generation DSI variances to determine whether it was appropriate for data to be pooled by year, location, and blocks (Ostle and Malone, 1988; Steel et al., 1997). The non-segregating $F_{1}$ and $F_{1} R$ generation means were subjected to a two-sample $t$ test of independence for detection of maternal effects on disease resistance (Steel et al., 1997).

An analysis of variance (ANOVA) was performed using PROC MIXED (SAS version 9.4) in which location and block effects were random, but generation was fixed because purposeful crosses were performed using parents with a previously observed disease response. Unbiased estimates of variance 
Table 1. Means, variances, and number of genotypes among generations of the basil MRI $\times$ SB22 full-sib family evaluated for response to downy mildew over 2 years at northern and southern New Jersey locations.

\begin{tabular}{|c|c|c|c|c|c|c|c|c|}
\hline Yr & Location & $\mathrm{MRI}^{\mathrm{y}}$ & $\mathrm{SB} 22^{x}$ & $\mathrm{~F}_{1}{ }^{\mathrm{w}}$ & $\mathrm{F}_{1} \mathrm{R}^{\mathrm{v}}$ & $\mathrm{F}_{2}$ & $\mathrm{BC}_{1} \mathrm{P}_{1}{ }^{\mathrm{u}}$ & $\mathrm{BC}_{1} \mathrm{P}_{2}{ }^{\mathrm{t}}$ \\
\hline \multicolumn{9}{|c|}{ Generation mean ${ }^{z}$} \\
\hline 2013 & Southern New Jersey & 0.000 & 0.986 & 0.104 & 0.133 & 0.265 & 0.575 & - \\
\hline 2014 & Southern New Jersey & 0.042 & 0.958 & 0.086 & 0.096 & 0.381 & 0.607 & 0.057 \\
\hline \multicolumn{9}{|c|}{ Generation variance ${ }^{s}$} \\
\hline 2013 & Southern New Jersey & 0.000 & 0.001 & 0.001 & 0.003 & 0.070 & 0.088 & - \\
\hline 2014 & Southern New Jersey & 0.002 & 0.002 & 0.005 & 0.004 & 0.109 & 0.128 & 0.006 \\
\hline \multicolumn{9}{|c|}{ Genotypes (no./generation) } \\
\hline 2013 & Southern New Jersey & 30 & 30 & 30 & 30 & 300 & 181 & - \\
\hline 2014 & Southern New Jersey & 30 & 30 & 30 & 30 & 300 & 180 & 144 \\
\hline 2014 & Northern New Jersey & 30 & 30 & 30 & 30 & 300 & 180 & 144 \\
\hline
\end{tabular}

${ }^{\mathrm{z}}$ Mean and variance estimates generated from disease severity index (DSI) scores of six mature leaves from individual plants.

${ }^{y}$ Resistant parent (P2).

${ }^{\mathrm{x}}$ Susceptible parent (P1).

"Maternal parent is SB22.

${ }^{v}$ Maternal parent is MRI.

"Backcross to the susceptible parent, SB22.

tBackcross to the resistant parent, MRI.

${ }^{\mathrm{s}} \mathrm{F}_{1}$ generations were not significantly different $(P=0.335)$ according to Fisher's two-sample $t$ test.

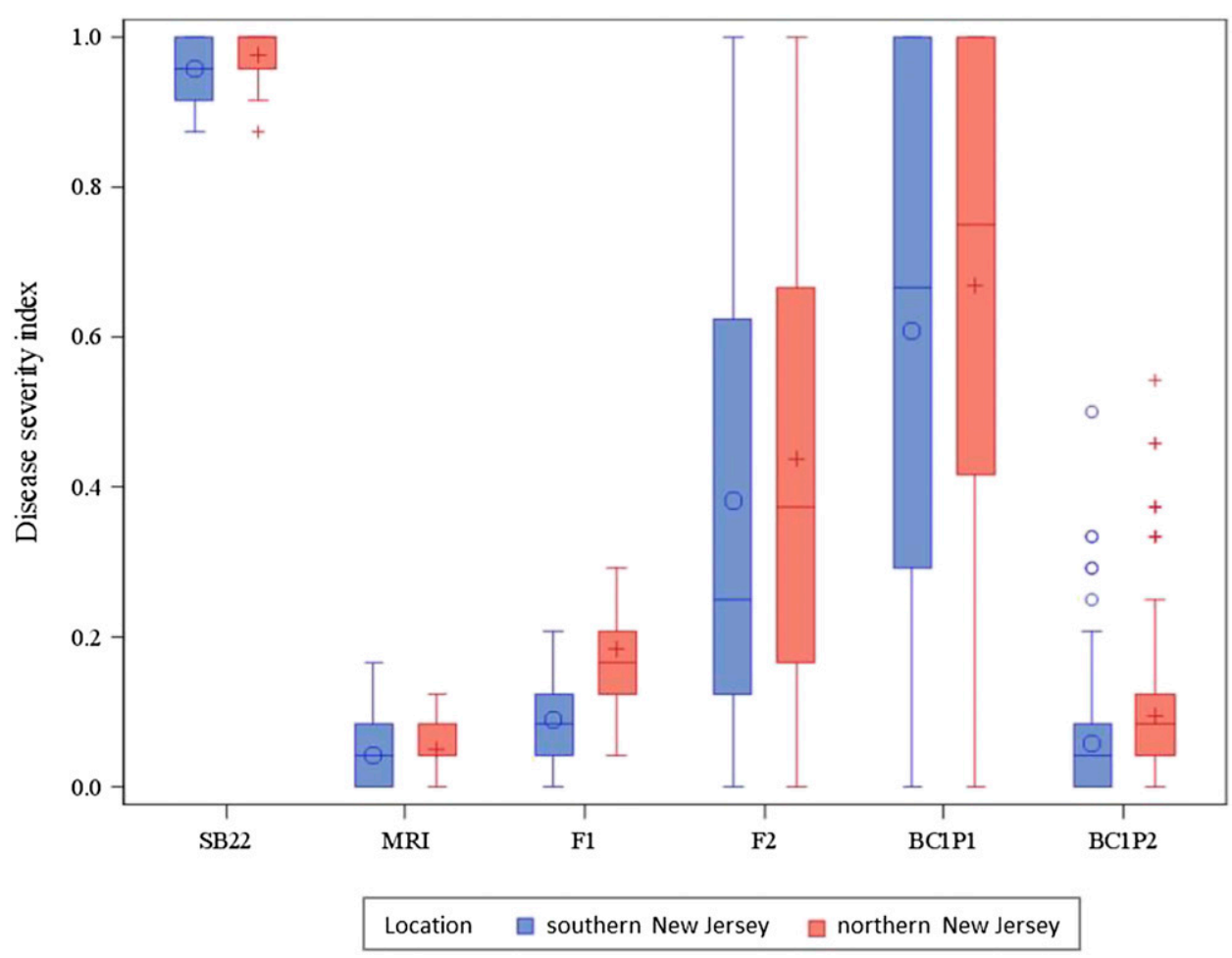

Fig. 2. Downy mildew response distributions for basil susceptible parent (SB22), basil resistant parent (MRI), $\mathrm{F}_{1}$, $\mathrm{F}_{2}, \mathrm{BC}_{1} \mathrm{P}_{1}$ (backcross to $\mathrm{SB} 22$ ), and $\mathrm{BC}_{1} \mathrm{P}_{2}$ (backcross to $\mathrm{MRI}$ ) generations in southern (blue, circle) and northern (red, cross) New Jersey locations in 2014. Boxes represent generation interquartile ranges, lines within boxes represent generation medians, and circles and plus signs within boxes represent generation means for southern and northern New Jersey, respectively. Whiskers represent disease severity index (DSI) ratings outside the interquartile range. Outliers are represented by circles and plus signs above the range of whiskers for southern and northern New Jersey, respectively.

were calculated for the effect of location $\left(\sigma^{2}\right)$, location $\times$ generation $\left(\sigma^{2}\right.$ lg $)$ and location $\times$ block $\left(\sigma^{2}\right.$ lb $)$ using the restricted maximum likelihood method. A mean separation was performed to determine differences among generations using the least significant difference $\left(\mathrm{LSD}_{0.05}\right)$ method.

To provide an estimation for the number of loci involved in disease response, five separate formulas were used to determine the minimum number of effective factors using the SASQuant 1.3 program (SAS version 9.4) (Gusmini et al., 2007). Five separate methods including Wright's method (Wright, 1968), Mather's method (Mather and Jinks, 1971), and Lande's methods I-III (Lande, 1981) provided five estimates from which an overall mean was calculated.

Chi-square tests were used to determine goodness of fit to hypothesized gene models based on observed and expected number of resistant and susceptible individuals in the $\mathrm{F}_{2}$ and $\mathrm{BC}_{1} \mathrm{P}_{1}$ generations. On the basis of comparisons of DSI scores with observed plant disease reactions in the field and analysis of generation frequency distributions, plants with a DSI score $<0.33$ (slightly more than $10 \%$ sporulation) were considered resistant. A portion of the population demonstrated a disease response within a DSI interval 0.33-0.66, which suggested an intermediate resistance reaction among these plants. In a similar study, Tetteh et al. (2013b) identified multiple hypothesized segregation ratios 
Table 2. Mean square and variance component estimates for response to downy mildew in the basil MRI $\times$ SB22 full-sib family pooled across northern and southern New Jersey locations in 2014.

\begin{tabular}{lccc}
\hline Source & df & Mean square & Variance component \\
\hline Generation & 5 & $17.114^{* *}$ & - \\
Block & 2 & $0.168 \mathrm{NS}$ & 0.000 \\
Location & 1 & $0.386^{*}$ & 0.001 \\
Block $\times$ location & 2 & $0.015 \mathrm{NS}$ & 0.000 \\
Generation $\times$ location & 5 & $0.024 \mathrm{NS}$ & 0.000 \\
\hline
\end{tabular}

*, **Significant at $P=0.05,0.001$, respectively.

NS $=$ nonsignificant.

Table 3. Least square means for response to downy mildew six generations of the basil MRI $\times$ SB22 full-sib family pooled across northern and southern New Jersey locations in 2014.

\begin{tabular}{lccc}
\hline Generation & $\mathrm{N}$ & Mean $^{\mathrm{z}}$ & $\mathrm{SE}$ \\
\hline $\mathrm{SB}_{2} 2^{\mathrm{y}}$ & 30 & $0.967 \mathrm{a}$ & 0.052 \\
$\mathrm{MRI}^{\mathrm{x}}$ & 30 & $0.047 \mathrm{e}$ & 0.052 \\
$\mathrm{~F}_{1}$ & 60 & $0.137 \mathrm{~d}$ & 0.046 \\
$\mathrm{~F}_{2}$ & 300 & $0.409 \mathrm{~b}$ & 0.041 \\
$\mathrm{BC}_{1} \mathrm{P}_{1}{ }^{\mathrm{w}}$ & 180 & $0.639 \mathrm{c}$ & 0.042 \\
$\mathrm{BC}_{1} \mathrm{P}_{2}{ }^{\mathrm{v}}$ & 144 & $0.076 \mathrm{de}$ & 0.042 \\
LSD $(5 \%)$ & 0.067 & &
\end{tabular}

${ }^{\mathrm{z}}$ Values with columns followed by the same letter are not significantly different at $P=0.05$ level according to least significant difference (LSD).

${ }^{y}$ Susceptible parent $(\mathrm{P} 1)$.

${ }^{\mathrm{x}}$ Resistant parent (P2).

${ }^{\text {w}}$ Backcross to the susceptible parent.

${ }^{v}$ Backcross to the resistant parent.

that could be fit to observed segregation ratios with and without an intermediate response. This approach was also used in this study by performing chi-square tests to determine goodness of fit to multiple hypothesized major gene models with the observed number of resistant, intermediate, and susceptible plants. In gene models that included an intermediate disease response (one incomplete dominant gene, two additive genes, and two genes with recessive epistasis), a DSI $>0.66$ (more than $40 \%$ sporulation) was considered downy mildew susceptible. In models that did not include an intermediate response (one dominant gene, two complementary genes, and two genes with dominant suppression epistasis), a DSI $>0.33$ was considered susceptible.

Addition of the $\mathrm{BC}_{1} \mathrm{P}_{2}$ generation in the 2014 field experiment permitted estimation of the main and epistatic gene effects affecting response to downy mildew. Gene effects were partitioned into six related parameters using a weighted least square regression of the extended joint scaling test (Hayman, 1958). Genetic parameters included the mean (m), additive (d), dominant $(\mathrm{h})$, additive $\times$ additive $(\mathrm{i})$, additive $\times$ dominant $(\mathrm{j})$, and dominant $\times$ dominant (l) effects. Standard errors and Student's $t$ significance level were calculated for all gene effects using the SASQuant 1.3 program (SAS version 9.4) (Gusmini et al., 2007).

\section{Results and Discussion}

The 2013 and 2014 results (Table 1) indicate the importance of multiyear evaluations when determining disease response to
$P$. belbahrii, a pathogen in which disease development is highly dependent on environmental conditions. Both the $2013 \mathrm{~F}_{2}$ variance and mean were significantly lower when compared with the $F_{2}$ data at either 2014 location (Table 1). A test of homogeneity of variances demonstrated a highly significant difference among $\mathrm{F}_{2}$ data across years $\left(\chi^{2}=15.28, P<0.001\right)$. Graphical analysis of the 2013 DSI frequency distribution and generation means revealed greater skewness toward resistance (data not shown) in comparison with the 2014 DSI distributions (Fig. 2), providing evidence that downy mildew pressure was significantly higher in 2014 than 2013 . Estimates of heritability can be skewed and segregation ratios distorted under conditions of insufficient selection pressure (Mather and Jinks, 1971). In the absence of adequate disease pressure, susceptible genotypes could be mistakenly selected as resistant and substantially reduce the effectiveness of plant breeding strategies. To provide the most representative measure of disease response, 2014 data were selected for subsequent statistical analysis of generation means, variances, and distributions. The $\mathrm{F}_{2}$ variances in 2014 were not significantly different when compared across blocks $\left(\chi^{2}=2.92, P=0.23\right)$ providing evidence that variation in disease response (phenotypic variance) could be achieved using $100 \mathrm{~F}_{2}$ individuals. An additional test for homogeneity of $\mathrm{F}_{2}$ variances among locations demonstrated no significant difference $\left(\chi^{2}=0.50, P=0.48\right)$ permitting 2014 data from northern and southern New Jersey to be pooled in subsequent statistical analyses.

Generation means and Variances. Significant differences $(P<0.001)$ were observed among generations of the MRI $\times$ SB22 family (Table 2). Mean DSI among parents demonstrated a differential response to downy mildew (SB22 DSI $=0.967$, MRI DSI = 0.046). This is the first report of resistance in genotype MRI, which was confirmed in this study in 2 years and two locations (Table 1). Although multiple downy mildewresistant basil accessions have been reported (Farahani-Kofoet et al., 2014; Pyne et al., 2014; Wyenandt et al., 2010), these genotypes are genetically divergent or taxonomically distinct from $O$. basilicum. Hybridization among $O$. basilicum species can be achieved through purposeful cross-pollination (Putievsky et al., 1999). Yet attempts to introgress disease resistance genes into traditional sweet basil by wide crosses or interspecific hybridization have been obstructed by sterility barriers (data not shown). These issues are likely due to significant differences in genome size and basic chromosome numbers in susceptible $O$. basilicum accessions and resistant basil species including $O$. americanum, $O$. kilimandscharicum, O. gratissimum, and O. tenuiflorum (Koroch et al., 2010; Paton and Putievsky, 1996). Identification of resistance in MRI provides a downy mildew-resistant parent that is fully cross-compatible with commercial sweet basil, suggesting similar genome constitution.

The $\mathrm{F}_{1}$ and $\mathrm{F}_{1} \mathrm{R}$ generations were resistant $(\mathrm{DSI}<0.33)$ and not significantly different $(P<0.335)$ according to a twosample $t$ test (Table 1), indicating that the resistance conferred by MRI is not maternally inherited and reciprocal $F_{1}$ generations could be pooled. A strong dominant effect was demonstrated by an $F_{1}$ mean (0.137) substantially lower than the midparent value of 0.506 and not significantly different from the MRI or the $\mathrm{BC}_{1} \mathrm{P}_{2}$ mean (Table 3 ). The absence of segregation in the $\mathrm{BC}_{1} \mathrm{P}_{1}$ generation suggested that $\mathrm{MRI}$ confers resistance through a dominant gene action. Both the $\mathrm{F}_{2}$ and $\mathrm{BC}_{1} \mathrm{P}_{1}$ generations demonstrated segregation for disease 
Table 4. Segregation in response to downy mildew (Peronospora belbahrii) among six generations of the basil MRI $\times$ SB22 full-sib family pooled across northern and southern New Jersey locations in 2014.

\begin{tabular}{|c|c|c|c|c|c|c|c|c|c|c|}
\hline \multirow[b]{3}{*}{ Generation } & \multicolumn{10}{|c|}{ MRI $\times$ SB22 family } \\
\hline & \multirow{2}{*}{$\frac{\text { Resistant }^{\mathrm{z}}}{0-0.33}$} & \multirow{2}{*}{$\frac{\text { Intermediate }}{0.34-0.66}$} & \multirow{2}{*}{$\frac{\text { Susceptible }}{0.67-1.0}$} & \multicolumn{7}{|c|}{ Probability of calculated $\chi^{2}$} \\
\hline & & & & $3: 1^{y}$ & $1: 2: 1$ & $9: 6: 1$ & $9: 7^{y}$ & $9: 3: 4$ & $12: 3: 1$ & $13: 3^{y}$ \\
\hline SB22 $2^{x}$ & - & - & 30 & - & - & - & - & - & - & - \\
\hline $\mathrm{F}_{1}$ & 60 & - & - & - & - & - & - & - & - & - \\
\hline $\mathrm{F}_{2}$ & 155 & 74 & 71 & $<0.01$ & $<0.01$ & $<0.01$ & 0.11 & 0.03 & $<0.01$ & $<0.01$ \\
\hline $\mathrm{BC}_{1} \mathrm{P}_{1}^{\mathrm{v}}$ & 44 & 32 & 104 & $<0.01$ & $<0.01$ & $<0.01$ & 0.04 & 0.63 & $<0.01$ & $<0.01$ \\
\hline
\end{tabular}

${ }^{2}$ Number of plants within each disease severity index class.

${ }^{\mathrm{y}} \mathrm{F} 2$ gene models. Corresponding ratios for the BC1P1 generation are 1:1, 0:2:2, 1:2:1, 1:3, 1:1:2, 2:1:1, 3:1. Ratios involving two disease response classes (single dominant gene, two complementary genes, and two genes with dominant suppression epistasis) correspond to the disease response segregation ratio $=$ resistant:(intermediate + susceptible).

${ }^{\mathrm{x}}$ Susceptible parent (P1).

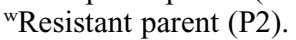

${ }^{v}$ Backcross to the susceptible parent.

"Backcross to the resistant parent.

Table 5. Gene effect estimates in response to downy mildew in the basil MRI $\times$ SB22 full-sib family pooled across northern and southern New Jersey locations in 2014.

\begin{tabular}{lccc}
\hline Gene effect & Estimate & SE & $P^{\mathrm{z}}$ \\
\hline Mean $(\mathrm{m})$ & 0.41 & 0.02 & $<0.001$ \\
Additive (d) & 0.56 & 0.02 & $<0.001$ \\
Dominant (h) & -0.58 & 0.15 & $<0.001$ \\
Additive $\times$ additive (i) & 0.88 & 0.14 & $<0.001$ \\
Additive $\times$ dominant (j) & 0.1 & 0.04 & $<0.001$ \\
Dominant $\times$ dominant (1) & 0.06 & 0.22 & 0.769
\end{tabular}

$\overline{\text { zProbability values determined by } t \text { test calculation using standard }}$ errors (SE) and df equal to the average number of individuals within segregating generations used to calculate each gene effect.

response with distributions that spanned from the lowest (0.0) to the highest (1.0) possible DSI scores (Fig. 2). The $\mathrm{BC}_{1} \mathrm{P}_{1}$ DSI mean was the highest among segregating generations and significantly greater $(P<0.05)$ than the next highest $\mathrm{F}_{2}$ generation mean (Table 3 ). The $\mathrm{F}_{2}$ DSI frequency distribution exhibited skewness toward resistance, while the $\mathrm{BC}_{1} \mathrm{P}_{1}$ distribution showed a substantial shift toward susceptibility (Fig. 2). Within the $\mathrm{BC}_{1} \mathrm{P}_{1}$ generation 44 genotypes (plants) or $24.4 \%$ were considered resistant (DSI $<0.33$ ), while 155 genotypes or $51.6 \%$ of the $\mathrm{F}_{2}$ generation were resistant.

Heritability. ANOVA was used to calculate all variation due to environment. ANOVA provided evidence that block, block by location, and generation by location effects were not significant (Table 2). Although the effect of location was significant at a $P<0.05$ confidence level, the variance component estimate of 0.001 was quite low relative to the segregating $\mathrm{F}_{2}$ and $\mathrm{BC}_{1} \mathrm{P}_{1}$ generations. Heritability can be described simply as the proportion of genetic variance (broad sense) or additive genetic variance (narrow sense) responsible for measured phenotypic variance, which includes genetic and environmental variances (Holland et al., 2003). In this study, the effect of location was a significant variance component of environment; however, it accounted for just $0.2 \%$ of the $\mathrm{BC}_{1} \mathrm{P}_{1}$ and $F_{2}$ variation. These estimates provide convincing evidence that the observed phenotypic variance across locations were largely attributed to genotypic variance. This is advantageous to breeding strategies, indicating that downy mildew response in the MRI $\times$ SB22 family is consistent across multiple locations given adequate disease pressure.

Gene ACTION. The presence of distinctly resistant, intermediate, and susceptible responses, suggests that downy mildew resistance in the MRI $\times$ SB22 family was under major gene control. Observed segregation ratios in the $F_{2}$ and $\mathrm{BC}_{1} \mathrm{P}_{1}$ populations were first tested for chi-square goodness of fit for monohybrid gene models (Table 4). Both single dominant and incomplete dominant expected ratios models were rejected at the $P<0.01$ confidence level, suggesting more than one locus was involved in the response to downy mildew. The number of effective factors, or loci, involved in response was estimated to be 1.4 (Wright's method), 5.2 (Mather's method), 1.1 (Lande's method I), 1.3 (Lande's method II), and 0.9 (Lande's method III). These estimates yielded an average of 2.0 and supported the major gene control hypothesis as well as the lack of evidence for single gene control. Although imprecise, these five estimates are useful in detecting control of resistance by a few major genes (Kozik et al., 2013). Multiple dihybrid gene models were evaluated and a chi-square test failed to reject the hypothesis for the two gene complementary $\left(\mathrm{F}_{2}: P=0.11\right.$, $\left.\mathrm{BC}_{1} \mathrm{P}_{1}: P=0.04\right)$ and recessive epistasis models $\left(\mathrm{F}_{2}: P=0.03\right.$, $\mathrm{BC}_{1} \mathrm{P}_{1}: P=0.63$ ) (Table 4). Both gene models suggest that digenic epistasis is involved in resistance to basil downy mildew, and a simple additive-dominant model is not adequate for describing the gene action. These results demonstrated that an extended scaling test was necessary for estimating significant nonallelic effects, which contributed to the variation observed in the MRI $\times$ SB22 family.

Additive (d) and dominant (h) gene effects were both highly significant $(P<0.001)$ and opposite (Table 5). A dominant, negative effect of -0.58 indicated involvement of a heterozygous resistant locus, whereas the positive additive effect of 0.56 indicated a homozygous, resistance-reducing locus. A highly significant $(P<0.001)$ additive $\times$ additive (i) gene effect of 0.88 provided the strong evidence for epistasis or the interaction of these loci. A positive value for the additive $\times$ additive effect suggests that interaction between homozygous loci results in a substantial resistance-reducing effect. Similarly, the 
additive $\times$ dominant $(\mathrm{j})$ interaction was positive and highly significant $(P<0.001)$, suggesting that homozygous and heterozygous loci were also interacting in a resistance-reducing capacity. Dominant $\times$ dominant (l) effects were not significant due to comparable $\mathrm{F}_{2}$ and $\mathrm{BC}_{1} \mathrm{P}_{1}$ generation means and a relatively high standard error of 0.22 (Table 5).

Results of the joint scaling test provide support for chisquare test hypotheses in which homozygous recessive alleles at either locus reduce the resistance response, while single dominant alleles confer resistance at a given locus. A significant and positive additive $\times$ dominant gene effect supports the recessive epistasis model in which a homozygous recessive locus masks expression of dominant resistance at a second locus. A very high additive $\times$ additive gene effect indicates that a significant interaction exists between homozygous recessive loci, which would result in complete susceptibility within a two-gene recessive epistatic model. Chi-square goodness of fit to the 9:7 ratio failed to reject the two-gene complementary hypothesis, which was further supported by the proximity of the $\mathrm{F}_{2}$ mean DSI (0.409) to the midparent mean DSI $(0.506)$ rather than the $F_{1}$ mean $(0.137)$. This depression in the $F_{2}$ population mean response suggests complementary epistasis (Hayman, 1958). Wang et al. (2001) demonstrated that true leaf downy mildew resistance in a broccoli doubled-haploid line was controlled by complementary epistasis based on goodness of fit to expected $\mathrm{F}_{2}$ and $\mathrm{BC}_{1} \mathrm{P}_{1}$ segregation ratios.

The development of additional populations and quantitative trait loci (QTL) is useful in providing greater resolution with regard to the interaction of loci conferring downy mildew resistance (Perchepied et al., 2005) and is needed to further elucidate gene action in the MRI $\times$ SB22 sweet basil family. A recent study by den Boer et al. (2014) found that QTL conferring field resistance to downy mildew in Lactuca saligna backcross inbred lines (BILs) resulted in "more-than-additive" and "less-than-additive" epistasis when intercrossed.

Epistasis has proven to be ubiquitous in plant resistance responses (Bnejdi et al., 2009; Fakhfakh et al., 2011; Keri et al., 1997) and in multiple instances of resistance to downy mildew (Perchepied et al., 2005; Shashikumar et al., 2010; Wang et al., 2001). Detection of nonallelic gene effects has important implications when designing effective breeding programs. Both complementary and recessive epistatic models introduce similar complexity to breeding efforts, but can be overcome using appropriate breeding and selection strategies.

Typically, dominant or "non-fixable" gene effects are exploited by hybrid breeding programs when possible (Fehr, 1987). In sweet basil, hybrid seed production is not a feasible breeding approach currently due to the meticulous nature of cross-pollinations and lack of an available doubled haploid protocol. A backcross breeding method using SB22 as the recurrent parent would be advantageous in decreasing undesirable phenotypes attributed to MRI (Fig. 1B). However, a 47\% decrease in disease-resistant individuals was observed in the $\mathrm{BC}_{1} \mathrm{P}_{1}$ generation relative to the $\mathrm{F}_{2}$ corresponding to a $50 \%$ decrease in the population gene frequency contributed by MRI. Therefore, large backcross populations would be required to overcome the frequency of recessive resistance-reducing alleles and achieve reasonable numbers of resistant individuals. Given the gene action described in this study, pedigree breeding would be a most effective approach in the fixation of dominant, downy mildew-resistant loci and the elimination of recessive alleles conferring susceptibility from the breeding population
(Fehr, 1987). Simultaneous selection for traits associated with SB22 (Fig. 1A) will yield downy mildew-resistant inbred breeding lines with a commercial sweet basil phenotype and chemotype.

This is the first characterization of genetic resistance to downy mildew in basil, as well as the use of six related generations in a single family to evaluate gene action. Results demonstrate that the use of this six-generation mating design was not only appropriate, but necessary for detecting the complex inheritance pattern controlling downy mildew resistance in the MRI $\times$ SB22 full sib basil family.

\section{Conclusion}

Results of this study indicate that resistance to basil downy mildew is controlled by digenic epistasis in the MRI $\times \mathrm{SB} 22$ family. Generation means, chi-square goodness-of-fit models, and the joint scaling test support the conclusion that dominant alleles confer resistance, whereas homozygous recessive alleles confer susceptibility. Breeding strategies should exploit the dominant gene action by fixing it at both loci and removing susceptibility alleles from the breeding population. This study provides evidence for a heritable form of downy mildew resistance that can be used to breed for genetic resistance in a commercial sweet basil.

\section{Literature Cited}

Belbahri, L., G. Calmin, J. Pawlowski, and F. Lefort. 2005. Phylogenetic analysis and real time PCR detection of a presumably undescribed Peronospora species on sweet basil and sage. Mycol. Res. 109:1276-1287.

Blomquist, C.L., S. Rooney-Latham, and P.A. Nolan. 2009. First report of downy mildew caused by a Peronospora sp. in San Diego County, California. Plant Dis. 93:968.

Bnejdi, F., M. Saadoun, M.B. Allagui, and M. El Gazzah. 2009. Epistasis and heritability of resistance to Phytophthora nicotianae in pepper (Capsicum annum L.). Euphytica 167:39-44.

Carlsson, M., R. von Bothmer, and A. Merker. 2004. Screening and evaluation of resistance to downy mildew (Peronospora parasitica) and clubroot (Plasmodiophora brassicae) in genetic resources of Brassica oleracea. Hereditas 141:293-300.

Cohen, Y., M. Vaknin, Y. Ben-naim, A.E. Rubin, D. Silverman, S. Bitton, and U. Adler. 2013. First report of the occurrence and resistance to mefenoxam of Peronospora belbahrii, causal agent of downy mildew of basil (Ocimum basilicum) in Israel. Plant Dis. 97:692.1-692.1.

De Masi, L., P. Siviero, C. Esposito, D. Castaldo, F. Siano, and B. Laratta. 2006. Assessment of agronomic, chemical and genetic variability in common basil (Ocimum basilicum L.). Eur. Food Res. Technol. 223:273-281.

den Boer, E., K.T.B. Pelgrom, N.Z. Zhang, R.G.F. Visser, R.E. Niks, and M.J.W. Jeuken. 2014. Effects of stacked quantitative resistance to downy mildew in lettuce do not simply add up. Theor. Appl. Genet. 127:1805-1816.

Fakhfakh, M.M., A. Yahyaoui, S. Rexgui, E.M. Elias, and A. Daaloul. 2011. Inheritances of Fusarium head blight resistance in a cross involving local and exotic durum wheat cultivars. Crop Sci. 51:2517-2524.

Farahani-Kofoet, R.D., P. Römer, and R. Grosch. 2012. Systemic spread of downy mildew in basil plants and detection of the pathogen in seed and plant samples. Mycol. Prog. 11:961-966.

Farahani-Kofoet, R.D., P. Römer, and R. Grosch. 2014. Selecting basil genotypes with resistance against downy mildew. Sci. Hort. 179:248-255. 
Farnham, M.W., M. Wang, and C.E. Thomas. 2002. A single dominant gene for downy mildew resistance in broccoli. Euphytica 128:405407.

Fehr, W. 1987. Principles of cultivar development. Vol. 1. Macmillan, New York, NY.

Garibaldi, A., D. Bertetti, and M.L. Gullino. 2007. Effect of leaf wetness duration and temperature on infection of downy mildew (Peronospora sp.) of basil. J. Plant Dis. Prot. 114:6-8.

Garibaldi, A., A. Minuto, D. Bertetti, and M.L. Gullino. 2004a. Seed transmission of Peronospora sp. of basil. J. Plant Dis. Prot. 111:465-469.

Garibaldi, A., G. Minuto, and M.L. Gullino. 2004b. First report of downy mildew on basil (Ocimum basilicum) in Italy. Plant Dis. $89: 312$.

Gilardi, G., S. Demarchi, A. Garibaldi, and M.L. Gullino. 2013. Management of downy mildew of sweet basil (Ocimum basilicum) caused by Peronospora belbahrii by means of resistance inducers, fungicides, biocontrol agents and natural products. Phytoparasitica 41:59-72.

Gusmini, G., T.C. Wehner, and S.B. Donaghy. 2007. SASQuant: A SAS software program to estimate genetic effects and heritabilities of quantitative traits in populations consisting of 6 related generations. J. Hered. 98:345-350.

Hayman, B.I. 1958. Separation of epistatic from additive and dominance variation in generation means. Heredity 12:371-390.

Holland, J.B., W.E. Nyquist, and C.T. Cervantes-Martinez. 2003. Estimating and interpreting heritability for plant breeding: An update. Plant Breed. Rev. 22:15-20.

Homa, K., W.P. Barney, D.L. Ward, C.A. Wyenandt, and J.E. Simon. 2014. Evaluation of fungicides for the control of Peronospora belbahrii on sweet basil in New Jersey. Plant Dis. 98:1561-1566.

Jensen, B.D., J. Hockenhull, and L. Munk. 1999. Seedling and adult plant resistance to downy mildew (Peronospora parasitica) in cauliflower (Brassica oleracea convar. botrytis var. botrytis). Plant Pathol. 18:604-612.

Jinks, J.J. and R.M. Jones. 1957. Estimation of the components of heterosis. Heredity 43:223-234.

Kanetic, L. and A. Vasiliou. 2014. First report of downy mildew caused by Peronospora belbahrii on sweet basil (Ocimum basilicum) in Cyprus. Plant Dis. 98:283.

Keri, M., C.G.J. van den Berg, P.B.E. McVetty, and S.R. Rimmer. 1997. Inheritance of resistance to Leptosphaeria maculans in Brassica juncea. Phytopathology 87:594-598.

Koroch, A.R., T.S. Villani, R.M. Pyne, and J.E. Simon. 2013. Rapid staining method to detect and identify downy mildew (Peronospora belbahrii) in basil. Appl. Plant Sci. 1:1300032.

Koroch, A.R., W. Wang, T.P. Michael, N. Dudai, J.E. Simon, and F.C. Belanger. 2010. Estimation of nuclear DNA content of cultivated Ocimum species by using flow cytometry. Isr. J. Plant Sci. 59:183-189.

Kozik, E.K., U. Klosinska, A.D. Call, and T.C. Wehner. 2013. Heritability and genetic variance estimates for resistance to downy mildew in cucumber accession Ames 2354. Crop Sci. 53:177-182.

Lande, R. 1981. The minimum number of genes contributing to quantitative variation between and within populations. Genetics 99:541-553.

Mahajan, V., H.S. Gill, and T.A. More. 1995. Inheritance of downy mildew resistance in Indian cauliflower (group III). Euphytica 86:1-3.

Martinez-de la Parte, E., L. Perez-Vicente, B. Bernal, and D. Garcia. 2009. First report of Peronospora sp. on sweet basil (Ocimum basilicum) in Cuba. New Dis. Rpt. 20:18.

Mather, K. and J.L. Jinks. 1971. Biometrical genetics: The study of continuous variation. 2nd ed. Chapman Hall, London, United Kingdom.

McLeod, A., S. Coertze, and L. Mostert. 2006. First report of a Peronospora species on sweet basil in South Africa. Plant Dis. 90:1115.
Mersha, Z., S. Zhang, and R. Raid. 2012. Evaluation of systemic acquired resistance inducers for control of downy mildew on basil. Crop Prot. 40:83-90.

Monteiro, A.A., P.S. Coelho, K. Bahcevandziev, and L. Valerio. 2005. Inheritance of downy mildew at cotyledon and adult-plant stages in 'Couve Algarvia' (Brassica oleracea var. tronchuda). Euphytica 141:85-92.

Nagy, G. and A. Horvath. 2011. Occurrence of downy mildew caused by Peronospora belbahrii on sweet basil in Hungary. Plant Dis. 95:1034.

Natti, J.J., M.H. Dickson, and J.D. Atkin. 1967. Resistance of Brassica oleracea varieties to downy mildew. Phytopathology 57:144-147.

Ostle, B. and L.C. Malone. 1988. Statistics in research. Iowa State Univ. Press, Ames, IA.

Paton, A., M.R. Harley, and M.M. Harley. 1999. Ocimum: An overview of classification and relationships, p. 1-38. In: R. Hiltunen and Y. Holm (eds.). Basil: The genus Ocimum. Harwood Academic Publ., Amsterdam, The Netherlands.

Paton, A. and E. Putievsky. 1996. Taxonomic problems and cytotaxonomic relationships between and within varieties of Ocimum basilicum and related species (Labiatae). Kew Bull. 51:509-524.

Perchepied, L., M. Bardin, C. Dogimont, and M. Pitrat. 2005. Relationship between loci conferring downy mildew and powdery mildew resistance in melon assessed by quantitative trait loci mapping. Phytopathology 95:556-565.

Putievsky, E., A. Paton, E. Lewinsohn, U. Ravid, D. Haimovich, I. Katzir, D. Saadi, and N. Dudai. 1999. Crossability and relationship between morphological and chemical varieties of Ocimum basilicum L. J. Herbs Spices Med. Plants 6:11-24.

Pyne, R.P., A.R. Koroch, C.A. Wyenandt, and J.E. Simon. 2014. A rapid screening approach to identify resistance to basil downy mildew (Peronospora belbahrii). HortScience 49:1041-1045.

Roberts, P.D., R.N. Raid, P.F. Harmon, S.A. Jordan, and A.J. Palmateer. 2009. First report of downy mildew caused by a Peronospora sp. on basil in Florida and the United States. Plant Dis. 93:199.

Shashikumar, K.T., M. Pitchaimuthu, and R.D. Rawal. 2010. Generation mean analysis of resistance to downy mildew in adult muskmelon plants. Euphytica 173:121-127.

Simon, J.E., J. Quinn, and R.G. Murray. 1990. Basil: A source of essential oils, p. 484-489. In: J. Janick and J.E. Simon (eds.). Advances in new crops. Timber Press, Portland, OR.

Steel, R.G.D., J.H. Torrie, and D.A. Dickey. 1997. Principles and procedures of statistics: A biometrical approach. WCB/McGrawHill, Boston, MA.

Tetteh, A.Y., T.C. Wehner, and A.R. Davis. 2013a. Inheritance of resistance to the powdery mildew race 2 in Citrullus lanatus var. lanatus. HortScience 48:1227-1230.

Tetteh, A.Y., T.C. Wehner, and A.R. Davis. 2013b. Inheritance of resistance to the new race of powdery mildew in watermelon. Crop Sci. 53:880-887.

Thines, M., S. Telle, S. Ploch, and F. Runge. 2009. Identity of the downy mildew pathogens of basil, coleus, and sage with implications for quarantine measures. Mycol. Res. 113:532-540.

Vieira, R.F., P. Goldsbrough, and J.E. Simon. 2003. Genetic diversity of basil (Ocimum spp.) based on RAPD markers. J. Amer. Soc. Hort. Sci. 128:94-99.

Wang, M., M.W. Farnham, and C.E. Thomas. 2001. Inheritance of true leaf stage downy mildew resistance in broccoli. J. Amer. Soc. Hort. Sci. 126:727-729.

Wright, J.N. 1968. The genetics of quantitative variability, p. 373-420. In: S. Wright (ed.). Evolution and genetics of populations. 2nd ed. Vol. 1. Univ. Chicago Press, Chicago, IL.

Wyenandt, C.A., J.E. Simon, M.T. McGrath, and D.L. Ward. 2010. Susceptibility of basil cultivars and breeding lines to downy mildew (Peronospora belbahrii). HortScience 45:1416-1419. 